\title{
Lignocellulosic Waste Material - from Landfill to Sorbent and Fuel
}

\author{
By Zorica R. Lopičić ${ }^{1}$, Mirjana D. Stojanović ${ }^{1}$ \\ Jelena V. Milojković ${ }^{1}$, Mirjana Lj. Kijevčanin ${ }^{2}$
}

\begin{abstract}
The most important source of renewable energy in Serbia represents biomass (60.3\%) with total potential of 3.405 million toe. Almost half of this amount (1.67 million toe) represents agricultural and industrial waste, with further negligible revalorization. Various investigations have demonstrated that agricultural byproducts have promising capacities to remove a variety of pollutants, which might increase the sustainability of their life cycle. This paper investigates the possible use of lignocellulosic waste material (LCW), originating from food industry as biosorbent for heavy metals, and later as a solid fuel. For this purpose we have used peach stone particles (PS) obtained by mechanical activation of this LCW as Cu(II) sorbent. The physical and chemical characteristics of PS reveal its complex structure which was confirmed by SEM, and FTIR analysis. PS behavior on pyrolysis process was studied by dynamic thermo gravimetric and derivate thermo gravimetric analysis. Results show that this lignocellulosic waste can be applied as sorbent and as a fuel. This approve that this agricultural waste can be a resource more than a waste and that it does not need to be disposed of in the costly and inefficient way, which is especially important in developing economies, like Serbian.
\end{abstract}

Keywords: biomass, lignocellulosic waste, pollution prevention, sorption, fuel

\section{Introduction}

Various industries, such as mining and smelting, surface finishing industry, energy and fuel production, fertilizer and pesticide industry and application, metallurgy, electroplating, electric appliance manufacturing, metal surface treating, etc., produce and discharge waste containing different heavy metals into the environment [1]. These metals found their pathway to waste waters from these industrial facilities and to surrounding natural water streams, presenting serious threat to the environment and human health. Heavy metal pollution is one of the most important environmental problems today because of non-biodegradability and possibility of metal accumulation in living organisms. The conventional, most commonly used techniques for removing heavy metals from wastewater include coagulation-precipitation, ion exchange, electrolytic extraction, filtration etc. Many of these techniques have certain limitations including high operational cost and energy requirements, incomplete removal and sludge that require further handling or disposal. For these reasons, there is a need to develop low-cost processes for heavy metal removal [2]. Biosorption is one of the promising processes for such type of removal, which can be defined as adsorption onto the surface of biomass through passive metal-bonding [3,4]. It is regarded as an effective option for heavy metal removal, especially at low concentrations [4].

Copper occurs naturally in the environment and spreads through the environment 
through natural phenomena. The production of copper has lifted over the last decades and due to this copper quantities in the environment have increased [5]. Soluble copper compounds form the largest threat to human health. The acute intake of copper leads to severe mucosal irritation, widespread capillary damage, hepatic and renal damage, central nervous problems followed by depression, gastrointestinal irritation, and possible necrotic changes in the liver and kidney [6]. The World Health Organization (WHO) recommended a maximum acceptable concentration of $\mathrm{Cu}$ (II) in drinking water of $1.5 \mathrm{mg} \mathrm{L}^{-1}[7]$.

Worldwide, depleting of non-renewable energy sources are causing a serious economical and environmental threats, leading to intensive research and investments in renewable resources. The most important source of renewable energy in Serbia represents biomass $(60.3 \%)$ with total potential of 3.405 million toe. Almost half of this amount (1.67 million toe) represents agricultural and industrial waste, unfortunately, with further negligible revalorization, where most of these wastes is disposed at open landfills. Peach (Prunus persica) has an important role in Serbia fruit production with average annual production of $96502 \mathrm{t}$ that generates more than $18000 \mathrm{t}$ peach stone (PS) waste [8]. This waste contains significant amount of lignocellulosic material which have been proven as renewable source of many chemicals, components and biofuels. On the other hand, in the Republic of Serbia electricity production is still based on the combustion of low rank domestic coals in thermal power plants and utilization of available hydro potential. Thus it is necessary to employ more renewable sources avoiding generation of waste and reducing environment pollution. Also, European Council Directive 1999/31/EC pronounces that bio waste with more than $3 \%$ organic content is no longer accepted for landfilling, intending to avoid uncontrolled GHG emission and soil and water pollution introducing strict technical requirements.

For all the reasons previously described, the authors have tried to investigate the possible way to use cheap, wasted material from agricultural and food industry in sustainable manner-as a sorbent and later as a bio based fuel. Considering life cycle of this waste material, we have concluded that it should be started from small enterprises, where this waste is generated and where it can be used to improve energy efficiency and promote more sustainable way of resources use.

\section{Material and Methods}

\subsection{Sorbent and sorbate preparation}

Peach stones were sampled from an open landfill in local Juice factory, where they have been disposed after fruits processing. After receiving, the stone samples were separated from fruit residues, washed, dried at room temperature, and kept in polypropylene bottles for further treatment. Prior to experiments, all the samples were crushed and separated from kernels, so for further analyse only hard stone part endocarp - was taken. Samples were mechanically treated - milled in ball mill, sieved and separated in several fractions. For the purpose of this paper, fraction with diameter of $0.5+0.1 \mathrm{~mm}$ was chosen. In order to eliminate surface impurities and open structure, sample was washed in $0.001 \mathrm{M} \mathrm{HCl}$ and then in distilled water, dried at $60^{\circ} \mathrm{C}$ until constant mass, marked as PS and kept in polypropylene bags prior to analysis. 
Copper solution was prepared by dissolving $\mathrm{CuSO}_{4} \cdot 5 \mathrm{H}_{2} \mathrm{O}$ (analytical grade) in distilled water using standard flasks. The initial metal concentration ranged from 10 to $300 \mathrm{mg} / \mathrm{L}$, and the initial $\mathrm{pH}$ value of solution was adjusted to 5 . During the experiment, the $\mathrm{pH}$ value of solution was kept constant by adding either $0.1 \mathrm{M} \mathrm{HCl}$ or $0.1 \mathrm{M} \mathrm{NaOH}$.

\subsection{Batch sorption experiments}

The removal of $\mathrm{Cu}(\mathrm{II})$ from its aqueous solution was conducted in batch reaction mode with stirring speed of $200 \mathrm{rpm}$. The experiments were done at an ambient temperature of $20^{\circ} \mathrm{C}, \mathrm{pH}=5$ and contact time of $180 \mathrm{~min}$.

The amount of $\mathrm{Cu}(\mathrm{II})$ uptake at equilibrium $q_{\mathrm{eq}}(\mathrm{mg} / \mathrm{g})$ and the removal efficiency, $\mathrm{R}(\%)$ were computed as follows:

$q=\frac{\left(C_{i}-C_{e}\right) \times V}{M}$

where $C_{\mathrm{i}}$ and $C_{\mathrm{e}}$ are the initial and equilibrium concentrations, given in $\mathrm{mg} / \mathrm{L}, V$ is the volume of solution (L), $M$ the weight of biosorbent used (g). Experimental data were fitted to three two-parameter isotherm models: Langmuir, Freundlich and Temkin.

\subsection{Analyses}

The total copper concentration was determined with atomic absorption spectrophotometer (Perkyn Elmer AAS Analyst 300) while the $\mathrm{pH}$ was determined by pH meter type Sension MM340. Surface functional groups were determined by Fourier Transform Infrared Spectroscopy (FT-IR) with a Thermo Scientific Nicolet iS50 spectrometer with a diamond attenuated total reflectance (ATR) smart accessory at a spectrum resolution of $2 \mathrm{~cm}^{-1}$ over a range of $4000-400 \mathrm{~cm}^{-1}$. Morphology of PS particles was observed using SEM model JSM - 6610LV (Jeol, Japan). Before the analyses, samples were dried $24 \mathrm{~h}$ at $60{ }^{\circ} \mathrm{C}$ and coated with gold. Thermal analysis of the samples was performed on a Netzsch STA 409 EP. Samples were heated $\left(20-1000{ }^{\circ} \mathrm{C}\right)$ in an air atmosphere with a heating rate of $15^{\circ} \mathrm{C} / \mathrm{min}$ and then kept in a desiccator at a relative humidity of $23 \%$, prior to analyses.

\section{Results and Discussion}

\subsection{Characterization of PS}

Chemical composition of PS revealed that this waste represents lignocellulosic material containing cellulose (62.94\%), lignin (17.93\%) and hemicellulose (5.42\%) [9] which indicates presence of many different functional groups that might be involved in copper removal, at the first place hydroxyl and carbonyl groups [10, 11]. This is confirmed by FTIR analysis which is presented in Figure 1. 


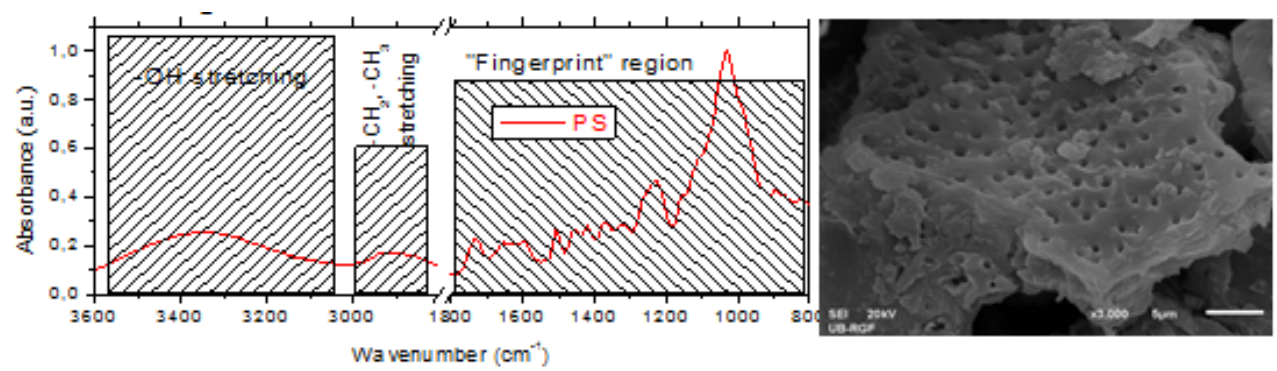

Figure 1. FTIR spectrum and SEM image of PS sample

As it can be seen from Fig.1, complex FTIR spectra of PS can be divided in two regions: first one in the range of $4000-2600 \mathrm{~cm}^{-1}$ which relates to $-\mathrm{OH}$ and $-\mathrm{CH}$ stretching vibrations, and the "fingerprint" region $\left(1800-800 \mathrm{~cm}^{-1}\right)$ characteristic for each material. It can be seen that the most representative bands in the first region are those assigned to -OH intramolecular and intermolecular stretching modes $\left(3600-3000 \mathrm{~cm}^{-1}\right)$ with strong peak at $3364.4 \mathrm{~cm}^{-1}$ and to symmetric and asymmetric methyl and methylene groups (3000-2800 $\left.\mathrm{cm}^{-1}\right)$. A very broad peak in the region between 3100 and $3600 \mathrm{~cm}^{-1}$ indicates the presence of exchangeable protons, typically from alcohol, amine, amide or carboxylic acid groups [12]. Significant peaks at $3579 \mathrm{~cm}^{-1}$ (O-H stretching from hydroxyl groups with intermolecular hydrogen bonding), $1733 \mathrm{~cm}^{-1}$ (indicative for free and esterified carboxyl groups, $\mathrm{C}=\mathrm{O}$ stretching), $1598 \mathrm{~cm}^{-1}$ and $1508 \mathrm{~cm}^{-1}(\mathrm{C}=\mathrm{C}$ ring stretching), 1053 $\mathrm{cm}^{-1}$ (C-O stretching in alcohols and carboxylic acid) are also observable. A peak at 1246 $\mathrm{cm}^{-1}$ is used to indicate the presence of structural carbohydrate such as celluloses, while the absorptions situated around 1510 and $1600 \mathrm{~cm}^{-1}$ (aromatic skeletal vibrations) are caused by lignin; the absorption located at $1730 \mathrm{~cm}^{-1}$ is caused by holocellulosecombination of cellulose and hemicellulose [13].

It can also be seen from Fig. 1 that PS poses multilayer structure with numerous macropores which enables fluid to penetrate into the internal layer of the material allowing deeper diffusion and better contact of $\mathrm{Cu}(\mathrm{II})$ ions with present functional groups. The average pore diameter of PS structure was found to be $28.5 \mathrm{~nm}$ [14] which is considered as desirable for diffusion and binding of metal species from aqueous solutions.

\subsection{Thermal behaviour of PS}

Thermogravimetric analysis (TGA) represents an important analytical technique which is used to study the thermal behaviour and characteristics of carbonaceous materials. Results obtained by TGA provide information on the material degradation process of occurring different temperatures. It is often used to predict biomass combustion behaviour. Interpretation of the experimental data can provide useful information about biomass composition and combustion kinetics. Chemical composition of PS and FTIR spectrum has confirmed that the main constituents of this material are hemicellulose, cellulose and lignin, complex natural polymers. Carbohydrate polymers (cellulose, hemicellulose), break down faster and provide volatile products, while the aromatic polymer - lignin goes through a slower degradation process [16]. TG and DTA curves of PS sample are presented on Fig. 2. 


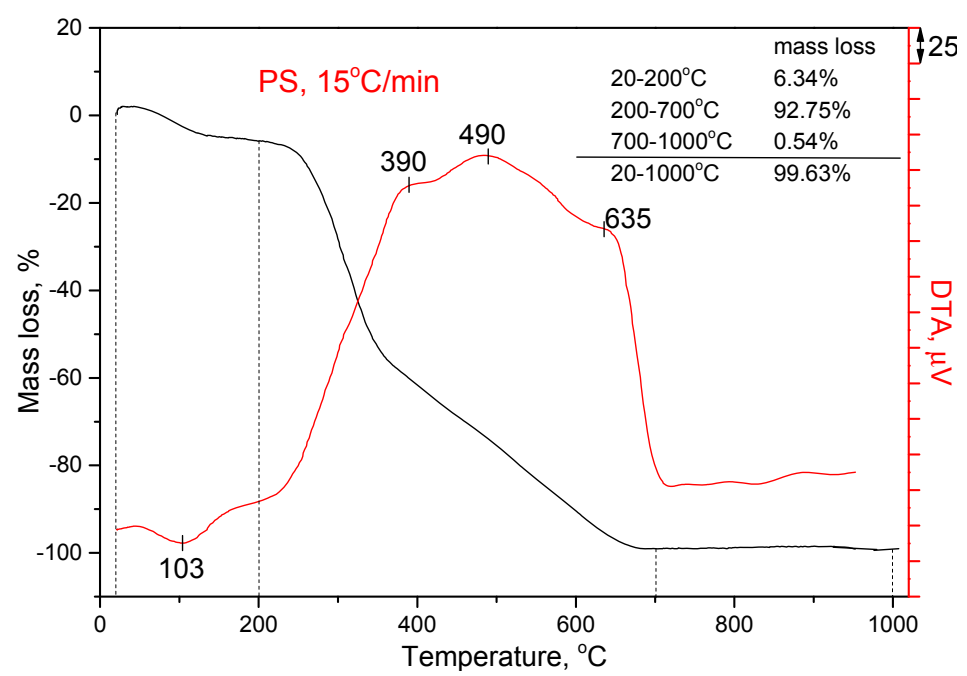

Figure 2. TGA and DTA curves of PS sample

TGA result of PS sample shows a typical three-stage mass loss:

- the first mass decomposition occurred around $100^{\circ} \mathrm{C}$, which can be attributed to water elimination/desorption. This water represents moisture, water molecules physically absorbed in PS. The DTA graph also shows an endothermic peak at $103^{\circ} \mathrm{C}$. In this region the loss of very small amount of volatile compounds may also be contributed to the weight loss.

- in the range from $200-400^{\circ} \mathrm{C}$ occurs the greatest mass loss (around $60 \%$ ) and two exothermic phenomena can be seen: they are both occurring due to the thermal decomposition of cellulose/hemicellulose portions.

- the third mass decomposition occurred between 400 and $550^{\circ} \mathrm{C}$, corresponding to the burning of complex aromatic lignin structure and exothermic peak at $490^{\circ} \mathrm{C}$ can be seen [17].

The TGA and DTA results indicate that this material can be used as a fuel, but, the development of feasible systems for efficient conversion of agricultural waste material, in this case peach stone, to energy by thermo-chemical conversion processes requires a fundamental understanding of its thermal properties and reaction kinetics, which should be further evaluated.

\subsection{Copper sorption}

Sorption experiments were conducted with PS particles whose diameter was between 0.1 and $0.5 \mathrm{~mm}$. According to our previous studies described elsewhere [9, 10], operational parameters were set as: $\mathrm{pH}=$ const $=5$, contact time $180 \mathrm{~min}$, ratio between sorbent mass and copper solution volume, $\mathrm{M} / \mathrm{V}=10 \mathrm{~g} / \mathrm{l}$. Copper concentration ranged between 10 and $250 \mathrm{mg} / \mathrm{l}$. In this paper are presented two most frequent isotherms used for describing equilibrium data: Langmuir and Freundlich. Langmuir isotherm is based on the assumption that monolayer adsorption is occurring on homogenous sites within the sorbent [18]. Another two parameter isotherm model, empirical Freundlich model, 
assumes that sorption occurs in multilayer, on heterogeneous sites [19]. Redlich Peterson isotherm incorporates both Langmuir and Freundlich model and can be applied in homogenous or heterogeneous systems [20]. Equation of these models together with corresponding parameter values obtained at $25^{\circ} \mathrm{C}$ are presented in Table 1 . Besides parameter values, this table contains the values of error functions which were used for goodness of fitting: non-linear coefficient of determination $\left(\mathrm{R}^{2}\right)$ and non-linear chi square test $\left(\chi^{2}\right)$.

Table 1. Parameters of equilibrium models for $\mathrm{Cu}(\mathrm{II})$ sorption onto $\mathrm{PS}$ at $25^{\circ} \mathrm{C}$

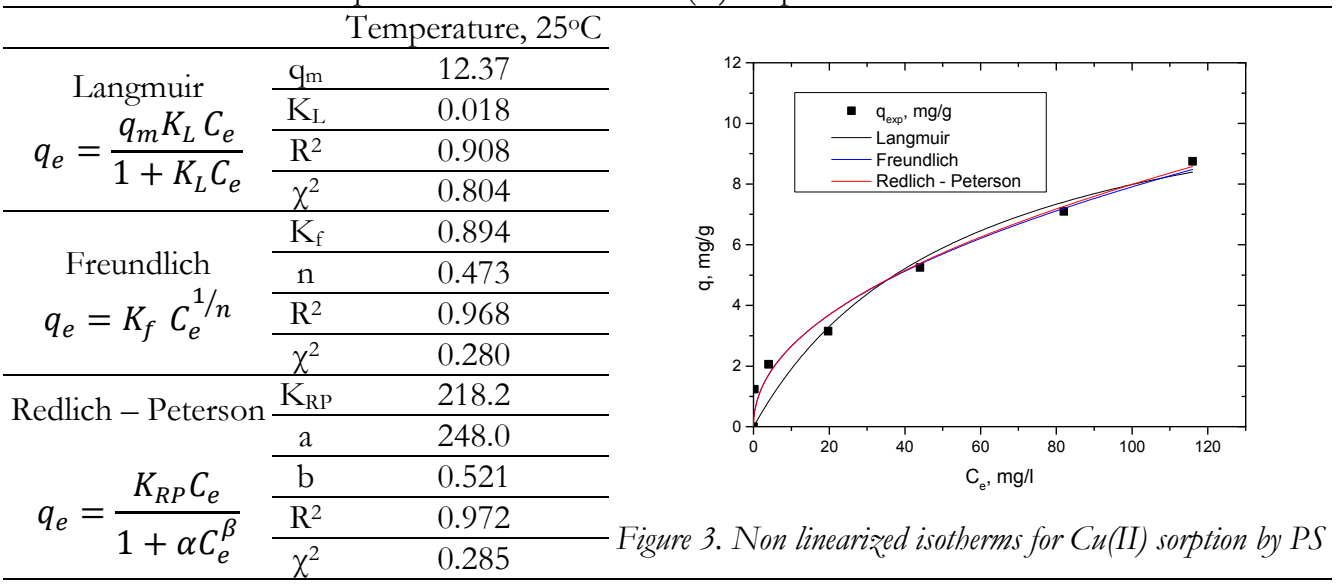

As it can be seen from Tab 1. and Fig. 3., model that best describes adsorption behavior of $\mathrm{Cu}(\mathrm{II})$ ions on peach stone particles with diameter between 0.1 and $0.5 \mathrm{~mm}$ is three parameters Redlich - Peterson model, based on lowest $\mathrm{R}^{2}$ and $\chi^{2}$ values. Maximum adsorption capacity obtained from Langmuir model, $12.37 \mathrm{mg} / \mathrm{g}$ reveals that, compared with other sorbents of natural origin, this type of sorbent have satisfactory capacity which should be further evaluated.

\section{Conclusion}

Due to its relative abundance and satisfactory adsorption capacity, the abundant waste from agricultural and food industry can be considered as a good low-cost adsorbent for removing copper ions from dilute aqueous solutions. The wider investigations should be done in order to define the best operating conditions for $\mathrm{Cu}$ (II) removing, as well as possible physical and chemical modifications that will enhance the pollutant. Results of characterization of this LCW material show that this lignocellulosic waste can be applied as sorbent and as a fuel. This approve that this agricultural waste can be a resource more than a waste and that it does not need to be disposed of in the costly and inefficient way, which is especially important in developing economies, like Serbian. The food and agriculture sector in the Republic of Serbia have a large potential to enable GHG emission reduction and improve environment quality, primarily through improve agricultural and environmental practices and wider utilization of agricultural waste residues for energy generation as the substitution of fossil based materials. Thus, 
the authors agree that the application of peach stone waste can reduce the implementation of fossil resources and in the same ime reduce negative impacts of human activities on the environment.

\section{Acknowledgement}

The authors are grateful to Serbian Ministry of Education and Science which support this research through its Project No TR 31003: "Development of technologies and products based on mineral raw materials and waste biomass for protection of natural resources for safe food production"

\section{References}

[1] Wang, J., and Chen, C. (2009). Biosorbents for heavy metals removal and their future. Biotechnology Advances, 27, 195-226.

[2] Yan, C., Li, G., Xue, P., Wei, Q., \& Li, Q. (2010). Competitive effect of Cu (II) and Zn(II) on the biosorption of lead(II) by Myriophyllum spicatum. Journal of Hazardous Materials, 179, 721-728.

[3] Yang Li, Brigitte Helmreich, Harald Horn, (2011). Biosorption of Cu(II) Ions from Aqueous Solution by Red Alga (Palmaria Palmata) and Beer Draff. Materials Sciences and Applications, 2, 70-80

[4] B. Volesky, "Review: Biosorption and Me," (2007). Water Research, 41, 18, 4017-4029

[5] Kalavathy, M.H. Karthikeyan T., Rajgopal S and Miranda L.R. (2005). Kinetic and isotherm studies of Cu (II) adsorption onto $\mathrm{H}_{3} \mathrm{PO}_{4}$-activated rubber wood sawdust. J. Colloid Interface Sci. 292, 354-362

[6] Gotoh, T., Matsushima, K., Kikuchi, K. (2004). Adsorption of Cu and Mn on covalently cross-linked alginate gel beads. Chemosphere, 55, 57-64.

[7] Rao C.S. (1992). Environmental Pollution Control Engineering, Wiley Eastern, New Delhi

[8] Statistical office of the Republic of Serbia, 2016. http://webrzs.stat.gov.rs/WebSite/ (accessed 01.04.16)

[9] Lopičić, Z., Milojković, J., Šoštarić, T., Petrović, M., Mihajlović, M., Lačnjevac, Č., Stojanović, M. (2013). Influence of $\mathrm{pH}$ value on $\mathrm{Cu}(\mathrm{II})$ biosorption by lignocellulose peach shell waste material. Hemijska Industrija 67, 1007-1015.

[10] Lopičić, Z.R, Stojanović, M.D., Marković, S.B., Milojković, J.V, Mihajlović, M.V., Kaluđerović-Radoičić, T.S., Kijevčanin, M. LJ. (2016). Effects of different mechanical treatments on structural changes of lignocellulosic waste biomass and subsequent $\mathrm{Cu}(\mathrm{II})$ removal kinetics. Arabian Journal of Chemistry, http://dx.doi.org/10.1016/j.arabjc.2016.04.005

[11] Torab-Mostaedi, M., Asadollahzadeh, M., Hemmati, A., Khosravi, A. (2013). Equilibrium, kinetic, and thermodynamic studies for biosorption of cadmium and nickel on grapefruit peel. J. Taiwan Inst. Chem. Eng. 44, 295-302.

[12] Socrates, G. (2001). Infrared and Raman Characteristic group frequencies: tables and charts, John Wiley and Sons ltd., London.

[13] Bodirlau R., Teacas, C.A. (2009). Fourier transform infrared spectroscopy and thermal analysis of lignocellulose fillers treated with organic anhydride. Rom. J. Phys. 54, 93-104.

[14] Marković, S., Stanković, A., Lopičić, Z., Lazarević, S., Stojanović, M., Uskoković, D. (2015). Application of raw peach shell particles for removal of methylene blue. J. Environ. Chem. Eng. 3, 716-724.

[15] Varhegyi, G., Antal, M.J., Szekely, T., Szabo, P. (1989). Kinetics of the thermal decom- position of cellulose, hemicellulose, and sugarcane bagasse. Energy Fuels, 3, 329-335.

[16] Saffe, M.A., Echegaray, M.E., Mazza, G.D., Rodriguez, R.A. (2014). Thermo gravimetric analysis of peach pits under inert and air atmosphere. International Journal of Engineering Science and Innovative Technology, 3, 21-30.

[17] AlOthman, Z. A., Habila, M. A., Ali, R., Abdel Ghafar, A., El-din Hassouna, M.S. (2014). Valorization of two waste streams into activated carbon and studying its adsorption kinetics, equilibrium isotherms and thermodynamics for methylene blue removal. Arabian Journal of Chemistry, 7, 11481158. 
[18] Langmuir, I. (1918). The adsorption of gases on plane surface of glass, mica and platinum. Journal of the American Chemical Society, 40, 1361-1368.

[19] Freundlich, H. M. F. (1906). Over the adsorption in solution. Journal of Physical Chemistry, 57, 385-470.

[20] Redlich O. and Peterson, D.L. (1959). A Useful Adsorption Isotherm. The Journal of Physical Chemistry, 63, 1024-1026. 